\title{
Beneficências Portuguesas no Rio Grande do Sul: de hospitais à associações promotoras da identidade lusa.
}

\section{Portuguese beneficences in Rio Grande do Sul: from hospitals to}

associations promoting the Lusa identity.

Recebido em: 28/12/2018

Aceito em: 04/01/2018

Larissa Patron Chaves ${ }^{1}$

\begin{abstract}
Resumo:
O trabalho recupera aspectos da história das Sociedades Portuguesas de Beneficência do Rio Grande do Sul na segunda metade do século XIX, especificamente nas cidades de Porto Alegre, Pelotas, Rio Grande e Bagé, e sua importância enquanto suporte assistencial, social e cultural em face ao fenômeno da imigração portuguesa para o Brasil durante o período. A Sociedade Portuguesa de Beneficência é uma instituição hospitalar criada por imigrantes portugueses no Brasil e no mundo colonial português, dependente do pagamento e de doações advindas, normalmente, dos seus associados. Na Província, as funções primordiais das beneficências pautavam-se pela promoção da representação pública dos imigrantes como indivíduos de boa educação e cultura, e também na promoção à devoção régia da monarquia portuguesa, o que revela relações simbólicas de poder, que atravessam o funcionamento dessas instituições. Neste sentido, o estudo analisa como o apoio e a proteção das Sociedades aos imigrantes e população em geral ultrapassara a função primordial de hospital para agregar questões de identidade e memória lusa no movimento à lusofonia.
\end{abstract}

Palavras-chave: Imigração Portuguesa. Hospitais de Beneficência Portuguesa. Identidades.

\section{Abstract: \\ The work recovers aspects of the history of the Portuguese societies of beneficence of Rio Grande do Sul in the second half of the nineteenth century, specifically in the cities of Porto Alegre, Pelotas, Rio Grande and Bagé, and its importance as assistance support, social and cultural relation to the phenomenon of Portuguese immigration to Brazil during the}

\footnotetext{
1 Professora Associada da Universidade Federal de Pelotas. Atua nos Programas de Pós Graduação em Artes Visuais e História, mestrado e doutorado. Doutora em História pela Universidade do Vale do Rio dos Sinos (2008) com estágio na Universidade do Porto, Portugal.
} 


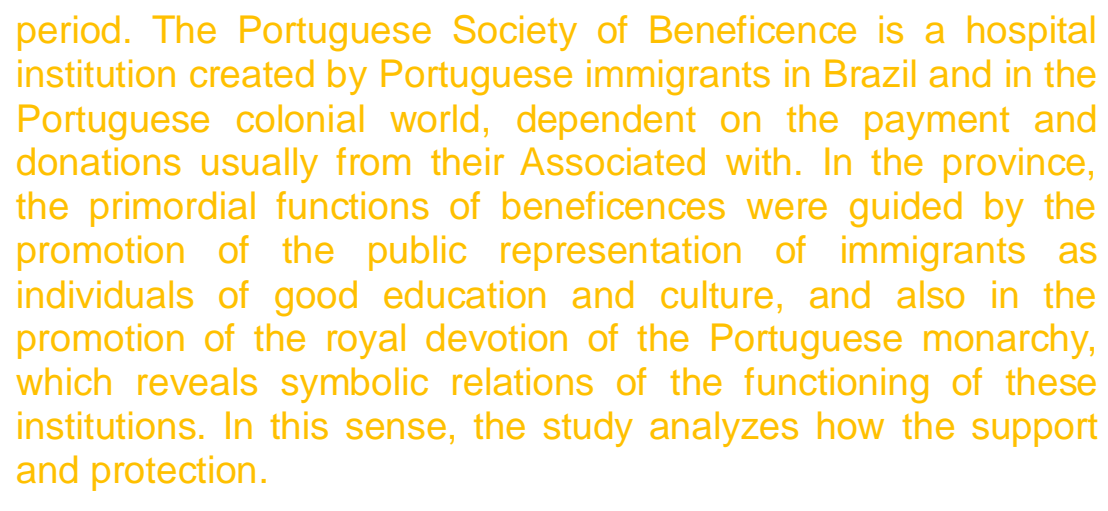

Keywords: Portuguese immigration. Portuguese beneficence Hospitals. Identities.

\section{A imigração portuguesa para o Brasil e as Sociedades Portuguesas de Beneficência.}

Na primeira metade do século XIX as autoridades governamentais do Império do Brasil adotaram uma política favorável a imigração para o país, sobretudo com relação à população advinda da Europa. A imigração subvencionada tem dois momentos marcantes na história do país: $1^{\circ}$ ) depois da vinda de Dom João VI, no início de 1808; $2^{\circ}$ ) depois da extinção do tráfico negreiro em 1850, e das posteriores e definitivas leis que extinguem a escravidão, como a do Ventre Livre, em 1871, e a Áurea, em 1888. Permeado por estes acontecimentos históricos, o tema da imigração européia para o Brasil na segunda metade do século XIX, largamente discutido na historiografia brasileira, é tratado sob o prisma da imigração centralizada, organizada e subsidiada pelo Estado, com atenção especial à origem das colônias de alemães e italianos. No entanto, como compreender a imigração portuguesa para o Brasil? Quando chegam os portugueses imigrantes no país? São os portugueses, recém chegados ao país, considerados imigrantes?

Dados numéricos sobre o movimento migratório para o Brasil são registrados no Instituto Brasileiro de Geografia e Estatística (IBGE). A estatística do porto do Rio de Janeiro mostra que aos 14 anos, decorridos de 1865 a 1878, entraram 388.459 estrangeiros que pela maior parte do país se fixaram. Nessa corrente de população entram os portugueses pelo número de 179.623, e os alemães pelo de 34.217 , o que demonstra a proporcionalidade dos elementos da nova população. ${ }^{2}$

\footnotetext{
2 Anuário Estatístico do Brasil. Ano I. Rio de Janeiro: Typographia da Estatística, 1916. Arquivo do instituto Brasileiro de Geografia e Estatística.
} 
Ainda, desse número de estrangeiros, aproximadamente 269.971 são homens e 118.488 são mulheres. No caso português, pesquisa realizada no livro de registros de imigrantes chegados ao Rio de Janeiro e Rio Grande do Sul (dois Estados do Brasil), entre os anos de 1860 e 1890, mostra que a maioria dos imigrantes lusos se identifica como operários, solteiros, entre 20 e 25 anos. Portanto, é menos comum encontrar o registro de um português que emigra com a família, pois sua vinda ao país consiste na ideia de trabalhar e enriquecer para posteriormente retornar a terra Natal. ${ }^{3}$

No ano de 1880 , entra no país um número total de 34.725 portugueses, sendo que 20 entram pelo porto de Belém; 23 pelo porto de Recife; 136 pelo porto de Salvador; 74 pelo porto de Victória; 20.335 pelo porto do Rio de Janeiro; 9.246 pelo porto de Santos; 109 pelo porto de Paranaguá; 8 pelo porto de Florianópolis e 84 pelo porto de Porto Alegre (as principais cidades portuárias da costa brasileira, de norte a sul). ${ }^{4}$

Os lusos recém chegados fazem parte da grande migração em massa que assola os países da América Latina entre os anos de 1860 e 1880. A imigração portuguesa para o Brasil pode ser encarada como um fenômeno análogo ao da imigração de outras nacionalidades como a francesa, ou a inglesa, e por isso, justificadamente, as condições de possibilidade que instigam essa população imigrante ao deslocamento são extremamente importantes enquanto fontes explicadoras do processo de desenvolvimento desse país.

Em Portugal, a partir de finais da década de 1850, iniciou-se a introdução do capitalismo no meio agrário, notadamente no Alentejo e no Ribatejo, formando companhias que se lançaram na agricultura comercial. Tal fato proporcionou, por um lado, um leve crescimento econômico, e por outro, uma forte migração populacional das zonas rurais para os centros urbanos (em decorrência da perda das pequenas propriedades rurais) ocasionando o início da sobre-população.

Posteriormente, um outro fator contribuinte à emigração dos portugueses para o Brasil foi a política orçamentária do seu país. Os problemas sociais e políticos de Portugal, de 1880 a 1890 , materializaram-se pelo comprometimento de $50 \%$ das receitas do Estado com a dívida pública. Nesse ponto, a perspectiva do sistema de governo baseado na doutrina liberal durante o século XIX, defendia que a emigração para as colônias era vantajosa para a economia das metrópoles. Isso porque constituía um mercado para as

\footnotetext{
${ }^{3}$ Livros de Registros da entrada de imigrantes na Província de São Pedro do Rio Grande. Ano: 1854-1889. Arquivo Instituto Histórico e Geográfico do Rio Grande do Sul.

${ }^{4}$ Anuário Estatístico do Brasil. Ano I. Rio de Janeiro: Typographia da Estatística, 1916. Arquivo do Instituto Brasileiro de Geografia e Estatística.
} 


\section{Memória}

manufaturas nacionais e promovia o investimento estrangeiro, permitindo o alívio das pressões provocadas pela sobre-população. Embora o Brasil na segunda metade do século XIX não fosse mais colônia de Portugal a muitas décadas, é sob essa visão que a emigração para o país foi encorajada pelas autoridades governamentais Portuguesas. ${ }^{5}$

Durante o Segundo Governo Imperial, o aumento populacional das muitas cidades e vilas em território brasileiro demandou a criação de instituições hospitalares sob a autorização e apoio do Governo Imperial. O mesmo ocorria do outro lado do Atlântico. Conforme afirma Joaquim Serrão (1978:243), vários diplomas são assinados pelos Governos de Regeneração em Portugal (1851-1868), entre eles, aqueles que apoiavam a criação de instituições hospitalares no Brasil, "pretendendo consolidar as relações políticas entre os dois países de fala e sentimentos portugueses..." (SERRÃO, 1978, p,243).

A Sociedade Portuguesa de Beneficência é uma instituição hospitalar criada por imigrantes portugueses no Brasil, e no mundo colonial português, a partir da segunda metade do século XIX. Além de atender aos associados na enfermidade e na morte objetivo principal dessas instituições - proporcionou suporte cultural ${ }^{6}$ e financeiro ${ }^{7}$ diante da omissão das autoridades governamentais brasileiras.

A mais antiga associação de Beneficência Portuguesa criada no Brasil foi a do Rio de Janeiro, em 1840, seguida por outra em Santos, em 1859. Em Pernambuco, muitas instituições de origem portuguesa foram criadas na segunda metade do século XIX, entre elas o Real Hospital Português de Beneficência para a comemoração da ascensão ao trono de D. Pedro V em Portugal, a 16 de Setembro de 1855.

Como instituição privada, dependente do pagamento e de doações espontâneas advindas dos associados, as Sociedades Portuguesas de Beneficência diferem das Santas Casas de Misericórdia, fundadas também no Brasil, cujo atendimento hospitalar é direcionado para a população em geral e as despesas subvencionadas pelo Império. No

\footnotetext{
5 O aumento da população urbana portuguesa é um fato insofismável a partir das últimas décadas do século XVIII. Essa tendência reforça-se a partir da década de oitocentos, com ritmos de crescimento das cidades da ordem de $77 \%$, entre 1864 e 1900, enquanto as freguesias rurais atingem em idêntico período $22 \%$. O litoral português, nomeadamente as duas cidades mais importantes, Lisboa e Porto, são manifestadamente incapazes de absorver todos os camponeses que a elas afluem em busca de trabalho e de melhores condições de vida, fato que terá como conseqüência inevitável o aumento da emigração. Sobre essas questões ver em SANTOS, Piedade Braga (org). Lisboa setentista vista por estrangeiros. Lisboa: Livros Horizonte, 1987.

${ }^{6}$ Exame realizado junto aos arquivos das Sociedades Portuguesas de Beneficência nas cidades de Porto Alegre, Rio Grande, Pelotas e Bagé mostrou que é presente na história das instituições a existência de uma Biblioteca. A doação de obras da literatura portuguesa e brasileira realizada pelos associados e pessoas das comunidades, contempla a função cultural que tais associações também pretendem cumprir.

$7 \mathrm{Da}$ mesma forma, é presente nos estatutos das instituições a ajuda ás famílias de sócios falecidos, na concessão de benefícios às viúvas e órfãos na forma de mensalidades pagas.
} 
entanto, em instituições de Beneficência Portuguesa, persistiram e persistem elementos que as situam sob o modelo das Misericórdias Portuguesas, criadas por Dona Leonor de Lancastre na Portugal do século XV, pois à semelhança das Misericórdias portuguesas, as Sociedades Portuguesas de Beneficência agem na circulação social da caridade tanto como um meio ético quanto como forma de perspectivar o favorecimento de determinados grupos e poderes elitários".

A questão religiosa não constituiu problema para os imigrantes portugueses no Brasil. Pelo menos em toda a América Latina, a herança da religião católica apostólica Romana foi incontestável, como uma tradição interposta não só por Portugal enquanto colonizador, mas por toda a Península lbérica. ${ }^{8}$

O envolvimento dos imigrantes portugueses na Sociedades Portuguesas de Beneficência da Província foi muito significativo, na medida em que são esses estrangeiros que as criaram e desenvolveram através do que chamaram de amor pátrio, promovendo a perpetuação dos valores cristãos através da prática da filantropia e caridade, virtudes maiores que projetaram o nome da Instituição nos locais onde funcionaram.

Na então Província de São Pedro do Rio Grande, a Sociedade Portuguesa de Beneficência da cidade de Porto Alegre inaugurou-se a 26 de Fevereiro de 1854. E, no decorrer de seu funcionamento, através do aumento do número de associados, ganha visibilidade regional, e funda agências em outras localidades que, em curto espaço de tempo, passam a congêneres. Foram elas nas cidades de Pelotas, em 1857, Rio Grande, em 1859, e Bagé, em 1871.

\section{As associações de Beneficência $e$ as suas atividades político-sociais como construtoras de identidade}

Relações de poder perpassaram as ações de caridade estabelecidas e préestabelecidas nas associações de beneficência. Neste sentido, as relações políticas e sociais que essas Associações no Rio Grande do Sul mantiveram com outras entidades locais (Câmara Legislativas, Intendências e partidos políticos), na maioria das vezes, se

\footnotetext{
${ }^{8}$ A filosofia cristã constitui a cosmovisão herdada da Europa, que materializa a vida no sentido bíblico onde, pelo menos hipoteticamente, todos os seres humanos são iguais perante Deus. Esse pensamento caracteriza a América Latina, distinguindo-a da América Anglo Saxónica, a qual traz consigo a referência no pensamento vigente aos países nórdicos. Tal pensamento, baseado na Reforma Protestante, prega a separação dos homens em povos eleitos e subordinados, a quem os eleitos devem comandar, por consequência de sua incapacidade intelectual e cultural.
} 
desenvolviam a partir da caridade, indicando peças chave de um tecido de estratégias políticas de alternância de exercício de poder. Da mesma forma, promoviam a celebração da identidade portuguesa, como instituições laicas sob a proteção régia portuguesa, tornandose, também, interlocutoras sociais, pois muitas de suas funções ultrapassaram 0 atendimento hospitalar, a exemplo, da promoção à devoção ao rei português, comemoração de efemérides, aniversários natalícios, integração e sociabilidade.

A inserção da cultura portuguesa, por meio das beneficências portuguesas, está atravessada por um tipo de assistência relacionado à dádiva como troca, que trás consigo estratégias de poder que se afirmam simbolicamente. Segundo Davis (2007), duas relações ligam a dádiva com a caridade numa determinada sociedade: a relação vertical e a relação horizontal do donativo. Dessa forma, produzem e reproduzem uma espécie de afirmação social, promovida desde a organização e as relações de poder entre sujeitos ligados a uma beneficência, até os objetos, documentos e regulamentos, e também as obras de arte, que contribuem para materializar essa perspectiva, como registra o relatório de 1867 da Associação em Porto Alegre,

\begin{abstract}
Senhores sócios
na parte moral a nossa é tão distinta como a mais digna das Associações, tendo tido já alguns sócios beneméritos pelos relevantes serviços prestados, tem aparecido constantemente muita dedicação em grande número de outros, e pode-se dizer sempre presidido todas as administrações tino, e morigeração o que te chamado para a nossa Associação a estima pública de que goza... ${ }^{9}$
\end{abstract}

Dessa forma, quaisquer que sejam as atividades políticas, sociais e culturais de uma beneficência portuguesa, elas devem ser avaliados a partir dessa perspectiva.

Em muitos dos relatórios analisados durante a condução da pesquisa de campo, encontramos elementos que revelaram as formas como as Associações se autodenominavam: associação patriótica; promotora de diversas dádivas aos sócios e imigrantes portugueses; brilhante atestado de filantropia "não somente da comunidade portuguesa mas da generosa família brasileira"; apóstolos da caridade, dentre outros, foram designações freqüentes, que sugeriram a tentativa das Sociedades Portuguesas de obter 0 reconhecimento de suas atividades como parte de seu aparato simbólico.

A preocupação com a existência de uma biblioteca, por exemplo, foi uma constante nestes relatórios analisados. ${ }^{10} \mathrm{O}$ fato de criarem espaços que privilegiassem a cultura, vinha

${ }^{9}$ Sociedade Portuguesa de Beneficência de Porto Alegre. Relatório apresentado em sessão de 13 de janeiro de 1867. Porto Alegre: Typographia do Jornal do Commércio, 1867. P. 30.

${ }^{10}$ No ano de 1875, a Sociedade Portuguesa de Beneficência de Campos, por exemplo, justifica a criação de sua biblioteca: "Por proposta do primeiro secretário, resolveu a diretoria criar no hospital uma biblioteca para uso dos 
de encontro a proposta de geração de benefícios aos sócios, ampliando suas possibilidades de atendimento. Um exemplo disso foi o caso da biblioteca da Sociedade Portuguesa de Beneficência do Rio de Janeiro que, em 1879, já contava com 2248 volumes.

$\mathrm{Na}$ Província de São Pedro do Rio Grande, uma das funções primordiais das beneficiências portuguesas, foi o empenho na promoção da representação pública dos imigrantes, associados enquanto indivíduos de boa educação e cultura. Na cidade de Rio Grande, por exemplo, a Sociedade construiu uma biblioteca em 1868 e, no mesmo ano, mandou transformar a fachada do edifício-sede, inspirada no Gabinete Português de Leitura no Rio de Janeiro. Da mesma forma, foram muitas as doações de obras literárias, portuguesas, brasileiras e de outros países, efetuadas pelos sócios lusos e por pessoas da comunidade rio-grandina, chegando em 1870, ao número de oitocentos volumes.

As atividades culturais desempenhadas pelas associações foram influenciadas pelo contato com suas congêneres no Brasil e no mundo colonial português. Elas utilizaram os eventos sociais como forma de perpetuar o seu poder nas sociedades onde foram criadas. É possível afirmar isso quando verificamos que, em todas as atas de fundação de locais como este, foram registradas solenidades com grandiosos saraus e Te Deum. ${ }^{11}$

As Associações de Beneficência da Província desenvolveram constantemente suas atividades sociais vinculadas à celebração da caridade, dado que contavam sempre com a presença das autoridades religiosas. Nesta perspectiva, demonstraram que, muitas vezes, as atividades sociais foram confundidas com as espirituais. Desta forma, as celebrações do aniversário natalício de cada instituição, ou em comemoração ao dia do seu Santo Padroeiro, por exemplo, foram considerados eventos sociais.

Nas Beneficiências Portuguesas estudadas foi possível observar a promoção a devoção régia à monarquia portuguesa. Como dito, uma instituição dessa ordem para existir no Brasil precisava do "apadrinhamento" de um Monarca Português. Dezenas de cartas foram emitidas pelas Sociedades Portuguesas de Beneficência endereçadas ao Ministério do Reino, em Portugal, mencionando, por exemplo, os seus respectivos funcionamentos administrativos; categorias de sócios; premiações; envio de doações ao Reino de Portugal (em virtude das enchentes do Minho e do Douro em 1851 e 1872, por exemplo);

doentes que a ele se recolhem. Esta medida, reclamada pela necessidade que prescreve ao espírito apreensivo do doente uma distração qualquer, e que até aqui não tinha, de certo devendo influir muito na cura, ainda lhe proporcionando fartos subsídios de conhecimentos indispensáveis e úteis ao homem..." Sociedade Portuguesa de Beneficência de Campos. Relatório, Ano 1875. Rio de Janeiro: O Globo, 1876. p. 45.

\footnotetext{
${ }^{11}$ Peça musical, de caráter sacro, criada para acompanhar uma missa solene de acção de graças que se inicia com a frase "Te Deum laudamus". Como hino litúrgico encontra inspiração em Santo Agostinho e Santo Ambrósio.
} 


\title{
memória
}

movimentos de receita e despesa das associações, entre outros temas. Em uma dessas cartas, assinada em 1872, por intermédio do Ministério dos Negócios estrangeios no Rio de Janeiro há o destaque para a situação da constituição e desenvolvimento da Sociedade de Beneficêcia de Bagé, na tentativa de garantir a proteção do príncipe português D. Carlos I,

\begin{abstract}
A diretoria da Sociedade Portuguesa de Beneficência de Bagé na província do Rio Grande do Sul requer por este Ministério que sua Majestade El Rei Ihe concedesse a Mercê de permitir que sua alteza real o sereníssimo (digníssimo) Dom Carlos para protector da referida Sociedade.....se vê que a sociedade està constituída de acrdo com os melhores auspícios, que brasileiros e estrangeiros de posição e bagè, se puseram a conadjuná-la com donativos e inscrevendo-se sócios cujo número excede jà a $400 \ldots . .{ }^{12}$
\end{abstract}

Com relação à proteção monárquica sobre as Sociedades Portuguesas, os retratos do rei funcionaram como marcadores da égide dos monarcas, aparatos simbólicos da proteção de Portugal, mostrando que a eficácia da presentificação do ausente, através da imagem, se dá pela sua representação.

De uma forma geral, percebe-se quão importante para as Associações de Beneficência de Porto Alegre, Rio Grande, Pelotas e Bagé, foi a demonstração da situação social de boa parte de seus associados. O apoio e a proteção do monarca português foi tão relevante quanto a projeção local/regional dos sócios, sobretudo para aqueles que fizeram parte de suas diretorias. Nesse sentido, a imagem do rei foi perpetuada através dos retratos nos salões oficiais.

A eficácia simbólica dessa imagem está no preenchimento do espaço vazio. Portanto, na medida em que representa o poder, a imagem assume uma importância para as Associações, que necessitavam de reconhecimento social nas localidades e também em Portugal.

Nos diversos relatórios da Sociedade Portuguesa de Beneficência da capital do Império, entre os anos de 1840 a 1889, observou-se que, na correspondência enviada a Portugal, já era referida a constante devoção aos monarcas lusos, conforme ilustra o texto:

\footnotetext{
Á Sua Magestade El Rei de Lisboa,

"Memorando a data querida do aniversário de suas Magestades El Rei e a Rainha de Portugal, a Real e Benemérita Sociedade Portugueza de Beneficência, renova jubilosa a Suas Magestades o preito da sua dedicação e respeito inquebrantáveis, fazendo todos os votos pela felicidade de Suas Magestades, da Real Família e da gloriosa Nação Portugueza". ${ }^{13}$
}

\footnotetext{
${ }^{12}$ Correspondência da Sociedade Portuguesa de Beneficência do Rio de janeiro. Ministério do Reino - Maço 5018, Proc 204, Liv. 03.

${ }^{13}$ Real Sociedade Portuguesa de Beneficência do Rio de Janeiro. Relatório. Ano 1888. Rio de Janeiro: Typografia O Globo, 1889.
} 
O recebimento de resposta pelas saudações enviadas configurava-se como um acontecimento especial e extremamente importante para as Sociedades de Beneficência. Todos os telegramas recebidos equivaliam a uma deferência significativa para as Instituições de Beneficência Portuguesa, um fato extraordinário, uma honra a ser invejada pelas demais associações de caridade existentes no Brasil.

O envolvimento emocional desses lusos com Portugal é flagrante, mesmo que não pudessem, a princípio, interferir em assuntos de ordem política em virtude da distância. A manutenção do patriotismo que aparecia em todas as comemorações portuguesas mostrava o desejo desses imigrantes de pertencer àquela pátria, e pelas características desse lugar ser por outrem interpretado.

Da mesma forma, os edifícios-sede das Sociedades Portuguesas de Beneficência caracterizam-se pelo estilo historicista eclético, guardando aspectos peculiares da função a que se destina o edifício agregados a ornamentação identitária, uma vez que materializam os desejos dos imigrantes portugueses de fazer parte de um grupo de elite.

Pierre Bourdieu (1972) revela que a compreensão imediata de determinada representação acontece pelas experiências que a mesma suscita, muitas vezes, afetivas, como simples sintomas culturais. O entendimento de uma simbologia, ou representação, depende de uma operação inconsciente de decifragem que só é perfeitamente adequada quando a competência que um dos agentes engaja na sua prática é igual a competência que engaja objetivamente o outro agente na percepção dessa simbologia, existindo para o autor, portanto, uma dependência das relações de força simbólica com respeito à estrutura das relações de força política. ${ }^{14}$

Os edifícios das sedes das Sociedades de Beneficência foram criados para serem compreendidos enquanto símbolo de um grupo que ascendeu socialmente, e portanto, os ícones lá deixados para representação foram feitos para a compreensão dos grupos sociais pertencentes também às elites locais. A pomposidade e luxuosidade característica do ecletismo, ilustra a situação de prosperidade do imigrante português no Brasil, símbolo de um grupo estrangeiro, que da mesma forma que prima pela boa conduta nos seus estatutos, anseia por uma apresentação visual impecável.

\footnotetext{
${ }^{14}$ Sobre essas questões ver em BOURDIEU, Pierre. Esquisse d 'une théorie de la pratique. Genéve, Lib. Droz, 1972. p. 48.
} 
Em relação à disposição interna e localização desses hospitais, elas se guiam pelas premissas dos médicos higienistas do século XIX, que atribuem as epidemias e a insalubridade das cidades da época colonial à sua conformação espacial: estreita e abafada. $^{15}$

No contexto da segunda metade do século XIX, essa "vontade coletiva" de "aperfeiçoamento moral", buscado através da solução dos problemas de higiene pública, muito concorre para a difusão de hospitais, sejam eles públicos ou privados. No decorrer de todo o Segundo Império, um grupo de médicos luta para conseguir prestígio junto às autoridades brasileiras, tentando estruturar e fortalecer a sua medicina, e com vistas a tornála a única forma legítima de curar. Para isso, é preciso realizar reformas e melhorias no interior da própria medicina, segundo Sampaio, e também se tornam fundamentais, a crítica e o combate às demais práticas de cura, tais como o curandeirismo, bastante arraigadas no cotidiano de diferentes grupos sociais e que representam uma séria concorrência aos métodos científicos, bem mais recentes no País (SAMPAIO, 1995)

No caso do hospital moderno, no qual se enquadram as Beneficências Portuguesas, o espaço arquitetônico interno é organizado para abrigar uma nova prática hospitalar, visto que alguns deles apresentam de forma bastante simétrica a separação dos leitos e salas cirúrgicas, de modo que se possa observar todos os doentes. Esta disposição interna higieniza e disciplina o espaço do hospital; ao mesmo tempo, é uma importante contribuição da prática médica européia, oriunda da época dos descobrimentos na área científica (séc. $\mathrm{XVI})$.

As exigências relativas às medidas urgentes de saneamento hospitalar e urbano permeiam o século XIX brasileiro. Elas têm como objetivo a separação do espaço físico dentro do hospital, segregação dos doentes, disciplinando esse mesmo espaço, e, dessa forma, colocando o homem em uma situação de "modelo", de "tipo". Essas transformações hospitalares, que remetem a Foucault - um indivíduo deve estar em cada lugar e em cada lugar um indivíduo (FOUCAULT, 1987) -, são medidas que também configuram-se como uma contribuição importante, pois é preciso passar pelo "sanitarismo despótico", um degrau necessário para que outras transformações médicas possam ocorrer, como ocorrem, nos séculos posteriores. A conformação espacial consagrada como ideal pelos órgãos que trabalham com a higiene pública no Brasil é encontrada em alguns hospitais das

\footnotetext{
${ }^{15}$ No Brasil, a implantação de uma nova malha urbana ocorre durante a República Nova, sobretudo no Rio de Janeiro, com o objetivo de curar os problemas de infra-estrutura e precariedade sanitária das cidades. Ver em PEREIRA, Sônia, A Reforma Urbana de Pereira Passos e Construção da Identidade Carioca (1996) p. 51.
} 
Beneficências Portuguesas.

No entanto, ao deparar-se com a história das Sociedades Portuguesas de Beneficência no Brasil, percebeu-se que esses hospitais não funcionaram somente como modelos, mas também como "lugares", representações de lusos que vivem em determinado local, sob determinadas condições.

Um dos casos que ilustram a construção de identidade na iconografia da fachada do edifício sede é o hospital da Beneficência de Rio Grande, que apresenta ao longo de sua história muitas modificações. A construção da primeira parte da edificação teve início no ano de 1857, quando pelo arrendamento dos prédios situados na praça da Geribanda, números dois e quatro (atual praça Tamandaré), foi erguida a primeira enfermaria. Após reivindicar a sua autonomia, a Sociedade de Beneficência de Rio Grande deixa de ser agência de Porto Alegre, em 1859, e nesse mesmo ano, começam as cotizações para a reforma da fachada do edifício-sede.

No entanto, foi somente no ano de 1868, que inicia-se a tão esperada reforma na fachada do prédio representativo da Instituição, que previa a sua reconstrução nos moldes do Gabinete Português de Leitura do Rio de Janeiro.

O edifício do Gabinete Português na capital do Império obedecia a uma arquitetura neo-manuelina, ou seja, ilustrativa de uma época áurea em Portugal, em que o próprio Dom Manuel ao imprimir nas artes e na cultura um estilo próprio português manifestava o enriquecimento da sociedade durante o século $\mathrm{XV}$, consequência dos descobrimentos e da oposição aos valores medievais, marcadores da Renascença portuguesa. No Rio de Janeiro, o Gabinete Português representou, e ainda representa, o símbolo da cultura portuguesa, pois configurou-se como guardião do saber nos inúmeros livros e periódicos que abriga.

De uma forma geral, a cópia da fachada do Gabinete Português representou para a Sociedade Portuguesa de Beneficência de Rio Grande uma maneira de equiparar-se com aquela Instituição, como detentora do saber e da cultura lusa, na garantia de obtenção de maior respeito e confiança por parte da população na cidade, e mais do que isso, do rei de Portugal à quem endereçavam correspondência.

A edificação é marcada pelo estilo neogótico, pela referência ao gótico medieval, misturado às novas técnicas de construção tão quanto o já trabalhado dentro do ecletismo. Da Antiguidade são buscadas as colunatas da Roma imperial; da Grécia antiga são trazidos 
os pórticos dóricos. Os temas alegóricos e exóticos são usados à exaustão. Este estilo foi empregado principalmente como alternativa ao neoclássico na construção de grandes igrejas. A presença do porão é comum na época. Balaústrada na platibanda e cornija logo abaixo, clássicas. Padieira em forma de cornija acima das janelas também é clássica, mas o elemento ornamental rebuscado quebra a formalidade comum ao clássico: a presença de platibanda em concreto com desenhos geométricos imitando os que eram produzidos nos gradis de ferro tão em moda, traços do art decor. No prédio da Beneficência Portuguesa de Rio Grande este estilo sofreu forte influência da arquitetura gótica.

Da mesma forma, percebe-se que o edifício também apresenta semelhança com o Monastério dos Jerônimos, um dos maiores monumentos exemplares da tipologia manuelina em Portugal, construído por Dom Manuel, também em 1498. Toda a referência à fachada de pedra do Monastério, sua imponência e decorativismo, já haviam sido retomados no Brasil em 1810, na construção do Real gabinete Português de Leitura do Rio de janeiro e de Pernambuco, sendo, nesse sentido, evocado também o aspecto de glória que há na organização estética e formal que representa esta tipologia, específicamente típica da Portugal no período do reinado de Dom Manuel. 
Figura 1: Gabinete Português de Leitura do Rio de Janeiro

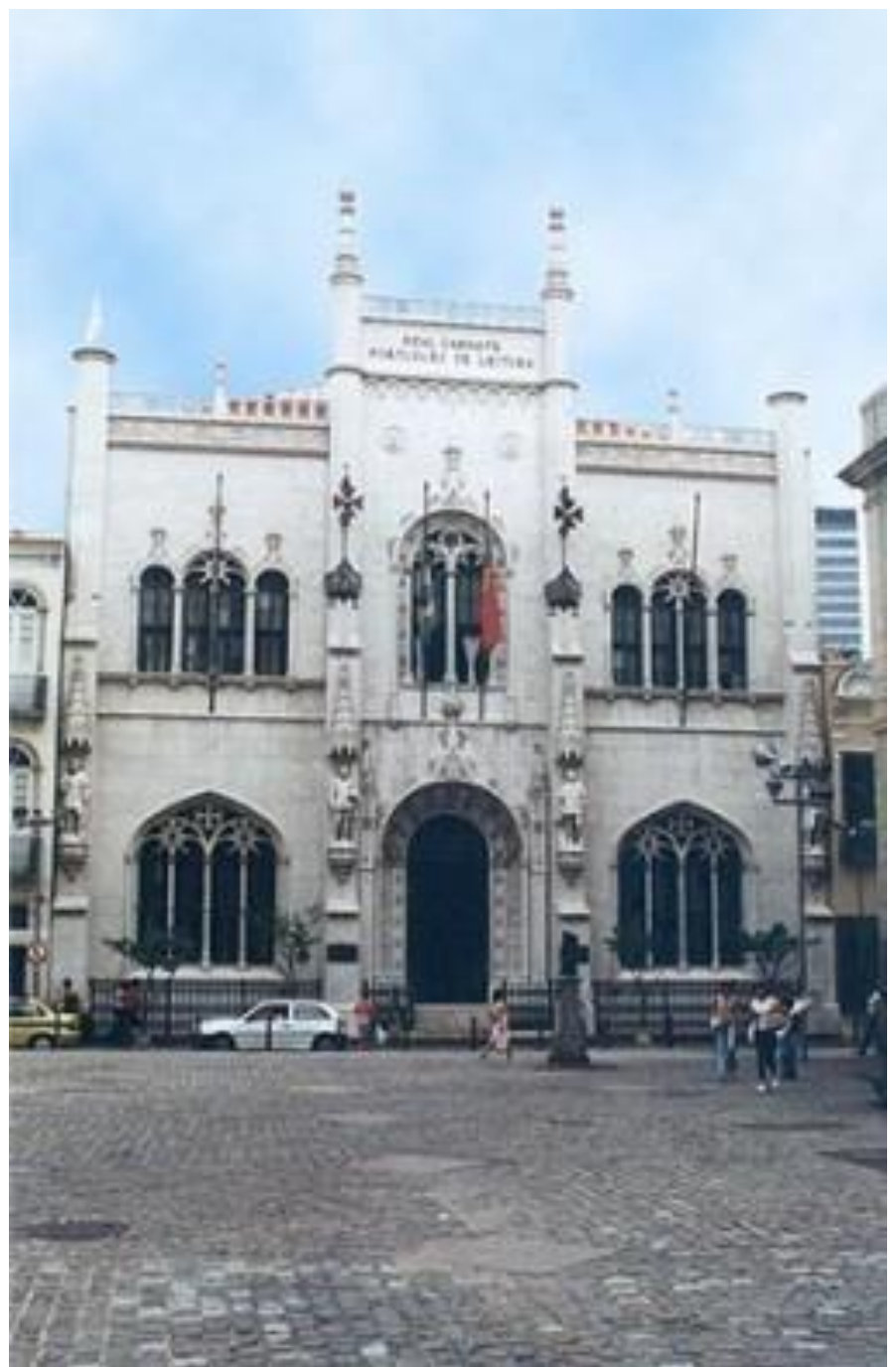

Fonte: Convergência Lusíada. Revista do Real Gabinete português de Leitura. N 14, 1997. 
Figura 02: Mosteiro dos Jerônimos, Lisboa.

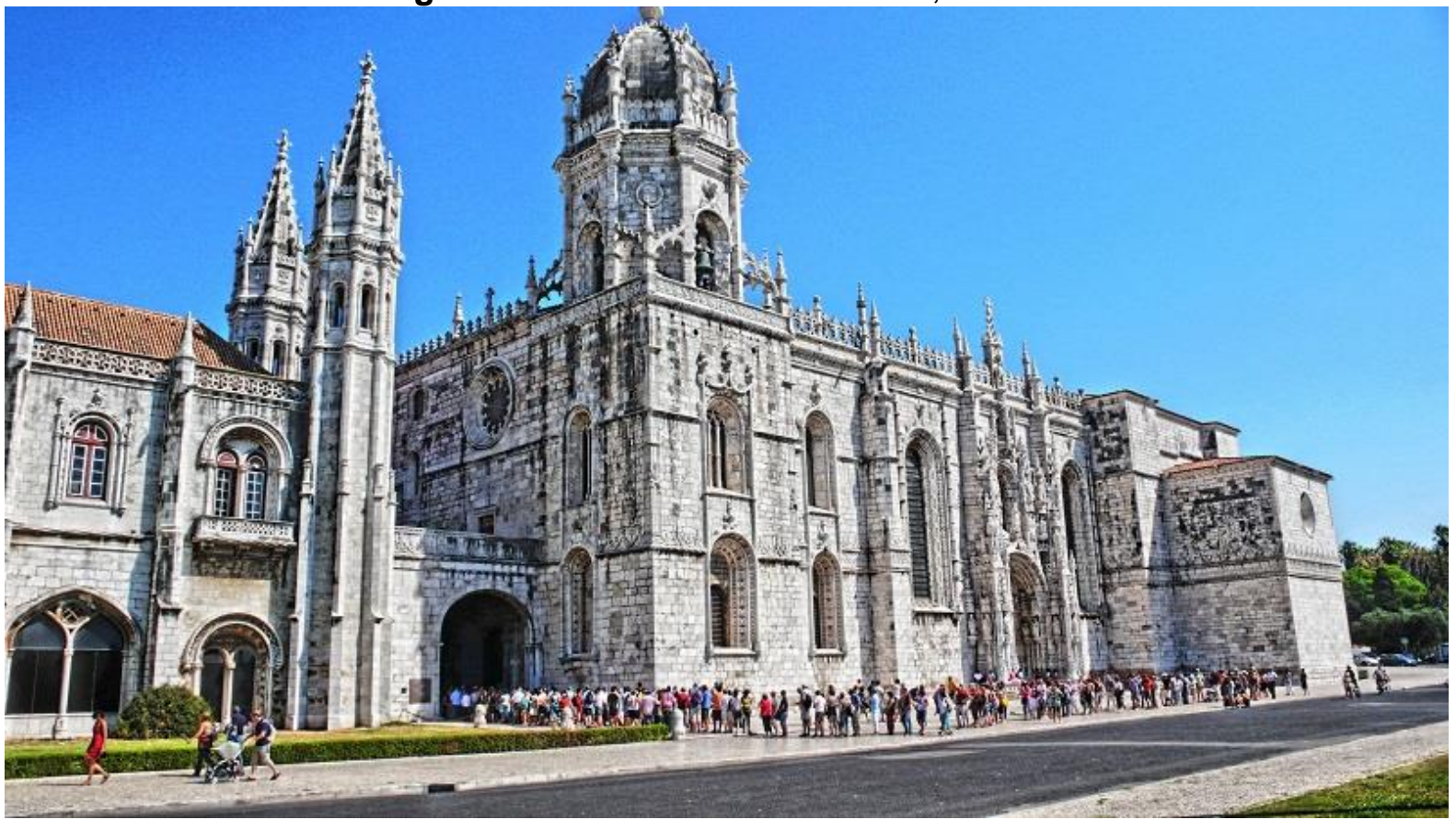

Fonte: https://br.pinterest.com/pin/523825000381539475/.

Figura 03: Fachada do prédio da Sociedade Portuguesa de Beneficência em Rio Grande

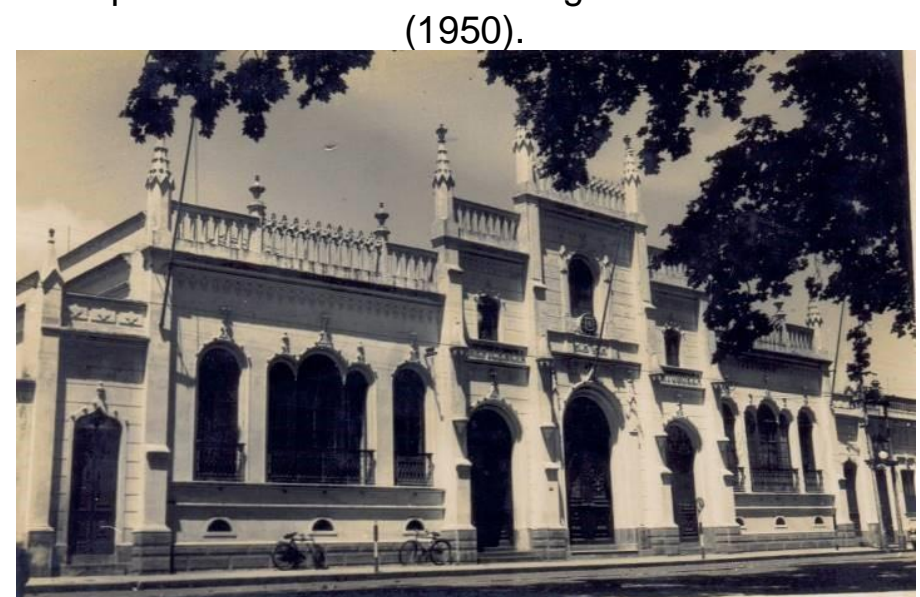

Fonte: Arquivo da Biblioteca Municipal de Rio Grande.

\section{A Beneficência e a memória social}

Os portugueses vinculados as Associações de Beneficência encontraram espaço para a realização e obtenção da assistência em diferentes momentos da história do Brasil, sobretudo quando a política Imperial sofria com a transição do regime governamental. $O$ trabalho assistencial efetuado pela Misericórdia portuguesa foi dado como um possível modelo, de um lado privilegiando a relação com a fë cristã, através da banderia da caridade, 
por outro perpectivando-se como instrumento político nas mãos do grupo diretivo, interessante para a manuntenção simbólica de Portugal no Brasil e também as elites locais.

Símbolos de distinção social foram efetivamente utilizados no decorrer da trajetória histórica das Sociedades Portuguesas de Beneficência do Rio Grande do Sul. De prédios representativos a cargos diretivos, a relação do destaque social esteve proporcional às Instituições e aos indivíduos que delas fizeram parte. É provável que em muitos momentos, a boa situação econômica e prestígio social das Instituições deva ter justificativa na troca de favores com as sociedades locais. Nesse sentido, conforme afirma Polanyi (1944), a teoria do mercado ligada a economia ainda é insuficientemente fundada para dar conta desses processos. Se existe uma forma que ultrapassa as relações de mercado, como por exemplo, relações de reciprocidade e de redistribuição, é porque o sistema de donativos são de fato baseados nas relações de poder ao mesmo tempo que de solidariedade. As associações de Beneficência durante o século XIX e início do XX ultrapassam a função primeira de hospital. Trocas de benefícios também foram importantes, pois contaram de alguma forma com a comunidade de associados para que pudessem reestruturar e renovar o hospital constantemente. Tudo isso fez e faz da Beneficência um lugar cheio de significados, onde a memória é constantemente revisitada e ressignificada.

Ao lançar luz sobre o processo histórico dessas instituições propõe-se, ainda, observar e analisar os espaços silenciosos dos lugares que narram a história. Constituem, em diferentes instâncias, as formas como estas instituições agiram sobre os movimentos de construção e reconstrução da identidade dos grupos de origem portuguesa em solo brasileiro.

\section{Referências}

BARTH, Fredrick (org.), Los grupos étnicos y sus fronteras. México: Fondo de Cultura Econômica, 1998.

BOURDIEU, Pierre. Esquisse d'une théorie de la pratique. Genéve, Lib. Droz, 1972.

CHAVES, Larissa Patron. "Honremos a Pátria Senhores! As Sociedades Portuguesas de Beneficência: caridade, poder e formação de elites na Província de São Pedro (1854-1910). Porto Alegre: Universidade do Vale do Rio dos Sinos. Programa de PósGraduação em História. Tese. 2008. 
DAVIS, Natalie Zemon. Essai sur le don dans la France du XVI siècle. Paris: Editions du Seuil, 2003.

FOUCAULT, Michel. Vigiar e Punir - a história da prisão. Petrópolis: Vozes, 1987.

FONTES E ARQUIVOS IMPRESSOS: Anuário Estatístico do Brasil. Ano I. Rio de Janeiro: Typographia da Estatística, 1916. Arquivo do instituto Brasileiro de Geografia e Estatística.

GUINZBURG, Carlo. Olhos de madeira - nove reflexões sobre a distância. São Paulo: Companhia das Letras, 2007.

Livros de Registros da entrada de imigrantes na Província de São Pedro do Rio Grande. Ano: 1854-1889. Arquivo Instituto Histórico e Geográfico do Rio Grande do Sul.

OLIVEIRA MARTINS, M. O Brasil e as colônias portuguesas. Lisboa: Verbo, 1978.

PEREIRA, Sônia. A Reforma Urbana de Pereira Passos e Construção da Identidade Carioca Rio de Janeiro: Zahar, 1996

Real Sociedade Portuguesa de Beneficência do Rio de Janeiro. Relatório. Ano 1888. Rio de Janeiro: Typografia O Globo, 1889.

SÁ, Isabel dos Guimarães. Quando o Rico se faz pobre. Misericórdias, Caridade e Poder no Império Português (1500-1800). Lisboa: Comissão Nacional para as Comemorações dos Descobrimentos Portugueses, 1997.

SAMPAIO, Gabriela dos Reis. Nas Trincheiras da Cura - As Diferentes Medicinas no Rio de Janeiro Imperial. Dissertação de mestrado apresentada ao Departamento de História da Universidade Estadual de Campinas. Campinas, 1995.

SERRÃO, Joaquim Veríssimo. História de Portugal. Lisboa: Editora Verbo, 1978. Vol. IV.

SILVA, Maria Beatriz Nizza da. Documentos para a história da Imigração portuguesa no Brasil (1850-1938). Rio de Janeiro: Federação das Associações Portuguesas e LusoBrasileiras, 1992.

SOUSA, Ivo Carneiro de. Da descoberta das Misericórdias às Misericórdias (1498-1525). Porto: Granito, 1999.

Sociedade Portuguesa de Beneficência de Bagé. Correspondência expedida.

Ministério do Reino - Maço 5018, Livro 03. Arquivo Nacional da Torre do Tombo. Lisboa, Portugal.

Sociedade Portuguesa de Beneficência de Campos. Relatório, Ano 1875. Rio de Janeiro: O Globo, 1876. p. 45.

Sociedade Portuguesa de Beneficência de Pelotas. Relatório, 1909. Pelotas: Tipografia Diário Popular, 1910: 35. 
Sociedade Portuguesa de Beneficência de Porto Alegre. Relatório, 1866. Porto Alegre: Typografia do Correio do Sul, 1866.p. 46.

Sociedade Portuguesa de Beneficência de Porto Alegre. Relatório, 1868. Porto Alegre: Tipografia Correio do Sul, 1868.

Sociedade Portuguesa de Beneficência de Porto Alegre. Relatório, 1870. Porto Alegre: Tipografia Jornal do Comércio, 1870.p. 26.

Sociedade Portuguesa de Beneficência do Rio de Janeiro. Relatório biênio (19041905). Rio de Janeiro: O Globo, 1908. p.111. 